\title{
The Research Review on Monitoring of Foundation Pit
}

\author{
S.M.Zhang J.Qian Q.Y.Zhang Y.S.Huang \& X.Q.Wang \\ Zhejiang University City College, Hangzhou, China
}

KEYWORD: Monitoring of Foundation pit, Construction safety, Technology development, Problem ABSTRACT: With the development of the city, the underground space are used in different ways at every city over the world, such us Multilayer basement of high-rise building, subway, underground market, as well as a variety of underground civil and industrial facilities. While increasing scale and the depth of the pit to make deformation and stability of temporary retaining structures become more complex and prominent, became the most important issues during the construction. On one hand, the increasing of plane size and depth raises several new issues are difficult to resolve based on existing theories. In other hand, with increasing intensity in all types of buildings of the city, the restrictions of deformation and adverse effects following construction are even more stringent. Monitoring of foundation pit engineering,especially the monitoring of deep Foundation pit during construction is very important.

\section{the research status at home and abroad}

In recent years, with the rapid development of China's economy and city construction, more and more underground engineering are beginning, the development and utilization of underground space became more and more important. Subway, underground garages, underground substations, underground shopping malls, underground civil defense project and Multilayer basement of highrise building are increasing ${ }^{[1]}$.

The foundation pit monitoring is a project of realize structure of foundation pit, the soil around the foundation and the adjacent structures to ensure the safety of the project ${ }^{[2]}$. Because the accident occurrence frequency sensitivity of late. The foundation pit monitoring is essential for foundation work. It is an important measures to ensure construction safety, and the focus and difficulty of construction $^{[3]}$. Foundation pit monitoring technology is become serious, and develops rapidly.

\section{Abroad research status}

In the 1930s, Terzaghi ${ }^{[4]}$ began to research the Geotechnical engineering problems in Foundation Pit engneering. After this, many scholars all over the world begin research, and made a lot of achievements in this field. In the 1940s, Tezrgahi and Peck put forward the total stress approach to Estimate stability of Earth excavation and Support load. This theory has been in use ever since, with many refinements and corrections. In the 1950s, Bjerrunr and Eide ${ }^{[5]}$ appear the approach of analysis floor heave in deep foundation pit. In the 1960s, became to monitoring with instrument in soft clay at Oslo and Mexico, then the accuracy of prediction increase with many measured data. And start from 1970s, Earth excavation standard is formulated. Venu Gopal Madhav Annamdas and Yaowen Yang ${ }^{[6]}$ publish of use electromechanical impedance(EMI) Technology in foundation pit monitoring. More and more new technology became be used in foundation pit monitoring.

\section{Domestic research status}

Start from 1980s, foundation pit engineering became Widespread. With the convening of the eleven session of the Third Plenary Session, Chinese beginning of the reform and opening-up policy, highrise and super high-rise building appeared, Foundation became deeper, foundation pit also became seeper. Especially in 1990s, most of the cities were entered in the size of the phase transformation of the old city. The new topic is excavation deep foundation pit in the busy urban ${ }^{[7]}$. In 1999,Zhiyong Zhang ${ }^{[8]}$ using the grey dynamic model GM(1,1), to process the observation data of settlement of buildings, to the prediction of the building settlement, achieved good results; in 2006, Xiaoqi $\operatorname{Lan}^{[9]}$ using time series analysis model, and combining with the practical example of building settlement monitoring, has carried on the analysis and forecasting of time series, demonstrated time series analysis model has better fitting precision and forecast accuracy; Li Wang $^{[10]}$ applied Calman filter model with examples, that is reasonable and reliable data processing 
of deformation using Calman filtering model in dam monitoring, can well predict the variation law system; In 2008, XiaoPeng Chen, Qiangyong Zhang and Dawen Liu ${ }^{[1]}$ application regression analysis algorithm, combined with the example of slope monitoring forecast analysis, draw the statistical regression analysis model to the deformation law and the change trend of slope well characterize the conclusion; in 2009,Haibo $\mathrm{Miu}^{[12]}$ using time series analysis method, combined with engineering example, through the analysis of deformation warning zone monitoring point displacement time series, based on the theory of judging the development trend of Baishuihe landslide deformation. Although some made some monitoring, but the monitoring data is not complete, or basically not to monitor processing analysis, conducts the research to the safety of the foundation pit monitoring and forecasting system is still unmanned system.

\section{research direction and progress}

\section{Monitor and perfect warning system}

The existing literatures, foundation pit monitoring and danger forecasting plays an important role in the safety construction in foundation pit engineering. According to the data of investigation, at present, domestic and foreign only use level gauge and Theodolite in most foundation pit, and the observation frequency differ rom man to man, sometimes a Monday times, sometimes once every ten days, or even longer. There are a few of the foundation pit using such as convergence gauge, reinforced concrete meter, the anchor cable dynamometer, but they are scattered in the non system. Now some large foundation pit construction, monitoring is an essential part.

Therefore the research on monitoring and forecasting system for foundation pit by Yong $\mathrm{He}^{[13]}$ has important significance. To illustrate, through the construction of real-time, complete is expected to improve the standards of the early warning system and can effectively improve the monitoring effect.

According to the foundation pit monitoring information, integration, sharing requirements, $\mathrm{Wu}$ Zhenjun $^{[14]}$ developed the distributed foundation pit monitoring information management and early warning system based on GIS.

\section{Enhance the measurement of accuracy of monitoring}

Foundation pit monitoring consists of depositing and displacement monitoring. depositing refers to the vertical movement of building foundation, foundation and ground produced under load, including the sinking and rising. Displacement refers to the non vertical building deformation. With the instrument the constant updating of equipment, precision instrument has been widely used in the foundation pit monitoring.

Jinyi Quan ${ }^{[15]}$ through the Daming Lake Road Ji'nan City Wu Yue Miao historic building protection monitoring of foundation pit project, settlement monitoring using high-precision total station, achieved good results.

Jiankun Zhang,Jin Wang ${ }^{[16]}$ were analyzed for free station method in foundation pit monitoring accuracy, put forward to use free station method for all aspects of foundation pit monitoring accuracy are very good promotion.

\section{The use of new technology}

There has been some system errors in deformation monitoring of foundation pit,so many new technologies are constantly being introduced the foundation pit monitoring among this industry. And some new technology also makes the foundation pit monitoring technology have made progress.

Yi $\mathrm{Li}^{[17]}$ through the Kaman filter in the deformation and the application of monitoring, using extended Kaman filter monitoring technology in existing in foundation pit monitoring. Thus through the technology to improve the technological level of the existing foundation monitoring.

Kanghu $\mathrm{Hu}^{[18]}$ studied to use the Matlab neuralnetwork Toolbox written in Elman neural network program of monitoring data, was established based the analog system of intelligent monitoring for Foundation pit engineering based on Matlab language. 


\section{the monitoring of tunnel around foundation pit}

Due to the increasing number of excavation, complex terrain is more and more, especially in the cities. The new problem is the influence to the tunnels and buildings around by excavation, we have to monitoring working on it. Passage point for real-time monitoring, timely access to information in the course of construction, its monitoring results can also be used to evaluate tunnel safety.

Yu Chen ${ }^{[19]}$,who analyzes the effect of excavation on down tunnel, combined the East Road overpass bridge project, using monitoring data in site. Results showed that: the influence of Metro tunnel by excavation, with soil's resilience and uplift, and approximate a normal distribution curve, and the hump is the maximum uplift points close to the excavation of the tunnel centre; Soil continued to show resilience in pit excavation, but due to the effect of structure load during construction, it has limited effect onspringback deformation, after the Foundation pit excavation in a long time; foundation pit excavation time and the Horizontal distance from excacation distance to tunnel axis level, have a really influence to tunnels displacement. And with the increase of the excavation time and space, tunnel heaving nonlinearly.

Longchuan Kuang ${ }^{[20]}$ research the Foundation pit excavation of Shanghai square, was measured lateral horizontal and vertical displacement of the tunnel around the foundation pit, and the chordwise deformation of tunnel Strip. Research results showed that: Excavation of deep foundation pit will make the tennel displacement to the foundation pit which around the it and deformation of tunnel is a horizontal oval shape; Pour mat floor in a timely manner to control further development of tunnel displacement; only to complete Foundation plate to tunnel displacement fundamentally stable. After the end of excavation of deep Foundation pit; Grouting correction at outside of the tunnel can correct lateral displacement of subway tunnel, but its effects are not very good.

Field measurement method can real-time monitor the tunnel deformation, and the data is reliable, can provide guidance for construction. But for the present, the vertical and horizontal displacement monitoring, less testing convergence of tunnel deformation and deformation of tunnel surrounding soil and earth pressure and pore-water pressure variation and limited number of measured points.

\section{problems and difficulties}

However, as the difficulty in foundation pit construction, the foundation pit monitoring actual, there still exist a lot of problems. The traditional maintenance support stress monitoring device is not reasonable to accurate measurement of numerical calculation ${ }^{[21]}$. The monitoring of the total cycle length and the monitoring frequency is high,resulting in artificial error caused by large monitoring ${ }^{[22]}$. Because of the actual situation, construction, including soil around the complex situation, leading to the actual situation of the design idea and foundation pit monitoring disconnect ${ }^{[23]}$.Due to the structure of the supporting structure and soil components of the complex, so the calculation results and actual value deviation etc.

\section{conclusion}

Due to the development of security problems in the reason and the underground space, foundation pit monitoring work will more and more appear in the research scope of each project. But with the new research and various techniques have been used to continue this work, foundation pit monitoring project will be the development of more and more perfect ${ }^{[24]}$.

As the system and standards of continuous monitoring of foundation pit will become clear, complete and into the industrial links of construction engineering system in. Through, after fresh technology to supplement and complement the foundation pit monitoring method for the old, the foundation pit monitoring business will radiate new vitality and ability ${ }^{[25]}$.

In the future, Foundation pit monitoring industry will reflect the new strength of this technology projects. 


\section{acknowledgement}

The work is fully supported by Science Technology Department of Zhejiang Province(2013C31041), and Ministry of Housing and Urban-Rural of Zhejiang Province (2014Z099), and Zhejiang University City College (J-15017).

\section{reference}

[1]Dongxiao Zhang.Construction of Monitoring and Forecasting System of Foundation Pit[D].Storage places:Central South University,2012:1-10.

[2]Ying Zhang.Research of Deep Excavation Monitoring Methods and Precision Requirement and Its Engineering Application[D].Storage places:Shandong University, 2012,3:1-8.

[4]Huang Mint.Predietion of Resolution and Homposition of Measured Displacement during Slope Exeavation[J].Chinese Journal of Roek Meehanies and Engineer. 2003,8:1320-1323.

[5]P.M.Naghdi.A New Derivation of the General Equations of Elastic Shells[J].International Journal of Engineering Science, 1965,3(3):335-337.

[6]Venu Gopal Madhav Annamdas and Yaowen Yang.Practical Implementation of Piezo-Impedance Sensors in Monitoring of Excavation Support Structures[J].Structural Controland Health Monitoring Struct. Control Health Monit.2012,9:231-245.

[7]Suping Jiang,Research and Application of Foundation Pit Monitoring Technology[D].master degree thesis of Central South University,2010,4:1-16.

[8]Zhiyong Zhang. Grey model prediction of settlement of buildings [J].City Survey.1999, (2):1013.

[9]Xiaoqi Lan,Yongping Yang,Qing Huang etc,Time Series Analysis and Prediction of the Building Settlement [J],Journal of Hohai University(NATURAL SCIENCE EDITION), 2006 ,34 (4): 426429.

[10]Li Wang.Application of Kalman wave Filtering in Monitoring Data Processing of Dam Deformation Dynamic[J].Journal of Xi'an University of Science And Technology.2006,26.

[11]Xiaopeng Chen,Qiangyong Zhang,Dawen Liu etc.Regression Analysis Model and Application of Statistical Slope Deformation[J].Journal of Rock Mechanics and Engineering.2008,(9).

[12]Haibo Miu,Kunlong Yin,Bo Chai etc.Prediction of landslide deformation based on nonstationary time series analysis[J].Geological Science and Technology Information 2009,28 (4): 10-112.

[13]Yong He.Research for Problems of Performance Monitoring and Safety Pre Excavation Engineering [J].Exploration of Science and Technology,2003,(44):29-33.

[14]Zhenjun Wu,Hao Wang,Shuilin Wang,Xiurun Ge.The Development of Distributed Foundation Pit Monitoring Information Management and Early Warning System[J].Rock and Soil Mechanics2008,(9):2503-2514.

[15]Jinyi Quan,Xingguo Zhang,Lei Wang.Application of High Pecision Measuring Instruments in Foundation Pit Monitoring [J].City Survey,2013(4):150-154.

[16]Jiankun Zhang,Jinming Wang,Liang Jia.Analysis of Free Stationing about Foundation Pit Monitoring Precision[J].Surveying and Mapping Engineering,2011,(8):74-77.

[17]Yi Li.The Use of Adaptive Kaman Filter in Data Processing of Deformation Monitoring [D].Chengdu University of Technology master thesis,2012,(6):107-119.

[18]kanghu Hu.Application about technology of foundation pit monitoring and early warning in the subway construction in Hangzhou [D].master's degree paper of Zhejiang University of Technology,2010,(4):1-36.

[19]Yu chen, Dongmei Zhang. The measured analysis of the foundation pit excavation to the Lying under the tunnel influence[J]. Chinese Journal of Underground Space and Enigeering, 2004, 24(5): 748-751.

[20]Longchuan Kuang. The influence of deep foundation pit excavation to the metro tunnel[J].Chinese Journal of Geotechnical Engineering, 2000, 22(3): 284-288.

[21]Huaxi Zhang.Discussion on Earthwork Excavation and support[J].Shanxi architecture, 2004,(7):54-55.

[22]Wei Han.Foundation Pit Monitoring and Environmental Protection in the Street of Deep Foundation Engineering [D].2002,(2):45-46. 
[23]Zhenbin Peng.The design calculation and Construction about Excavation and Support of Deep Foundation Pit Engineering[M].Wuhan China University of Geosciences Press, 1997(7):76-79.

[24]Linjie Zhao ,Minglong Zhao ,Zhian Jiang ,Guopeng Yang .Deviational Survey Technology Applied in Deep Foundation Pit Monitoring [J].Tunnel Underground Engineering,2011,(11):109116.

[25]Haibo Huang.Discussion on Foundation Pit Monitoring Technology Applied in Deep Foundation Pit [J].Innovation and Application of Science and Technology 2012,(8):208-211. 